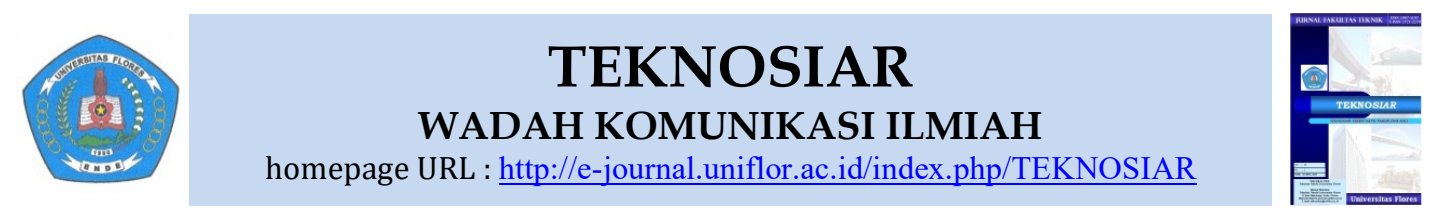

\title{
Studi Perbandingan Karakteristik Agregat Quarry Nangapanda Dan Quarry Aemau Untuk Lapis Pondasi Bawah (Sub Base)
}

\author{
Blasius D.Nosemba ${ }^{1}$, Thomas Aquino A.Sydin ${ }^{2}$, *Fransiskus X .Ndale ${ }^{3}$ \\ ${ }^{1}$ Alumni Program Studi Teknik Sipil, Fakultas Teknik, Universitas Flores, Ende \\ ${ }^{2,3}$ Dosen Program Studi Teknik Sipil, Fakultas Teknik, Universitas Flores, Ende \\ *) Correspondence, e-mail: milanonet66@gmail.com
}

Received: 01-04-2021 Revised: 12-04-2021 Accepted: 27-0402021

\begin{abstract}
ABSTRAC
One of the constituent materials of road pavement is aggregate, for that it is necessary to do research on the characteristics of aggregate material as the basic material for road construction. The Nangapanda quarry and the Aemau quarry are the sources of material that are often used for road construction in Ende and Nagekeo Regencies. The purpose of this study was to determine the aggregate characteristics of the Nangapanda quarry and the Aemau quarry, as well as to compare their characteristics for the sub base layer. The method used is the Indonesian National Standard (SNI). The results of the analysis of the sieve analysis of the two quarry aggregates are included in the typical uniform gradation, the bulk density of the Nangapanda quarry is 2.53 and the Aemau quarry is 2.84. The absorption for the Nangapanda quarry is $2.81 \%$ and the Aemau quarry is $1.60 \%$, the aggregate moisture content of the Nangapanda quarry is $1.51 \%$ and the Aemau quarry is $1.075 \%$, the aggregate that passes the number $200(0.075 \mathrm{~mm})$ for the Nangapanda quarry is $0.283 \%$ and the Aemau quarry $0.423 \%$, the aggregate wear of the Nangapanda quarry is $18.30 \%$ and the Aemau quarry is $12.06 \%$. The final results of these two quarry aggregates have met the SNI requirements with a comparison of the characteristics of the Aemau quarry aggregate which is better than the Nangapanda quarry aggregate.
\end{abstract}

Keywords: road construction, aggregate, foundation layer, quarry

\begin{abstract}
ABSTRAK
Salah satu bahan penyusun perkerasan jalan adalah agregat,untuk itu perlu dilakukan penelitian terhadap karakteristik material agregat sebagai bahan dasar konstruksi jalan. Quarry Nangapanda dan quarry Aemau merupakan sumber material yang sering digunakan untuk pembangunan pekerjaan jalan di Kabupaten Ende dan Nagekeo. Tujuan Penelitian ini untuk mengetahui karakteristik agregat quarry Nangapanda dan quarry Aemau, serta perbandingan karakteristiknya untuk lapis pondasi bawah (sub base). Metode yang digunakan adalah Standar Nasional Indonesia (SNI). Hasil pengujian analisis saringan agregat dua quarry ini termasuk dalam tipikal gradasi seragam,berat jenis (bulk) quarry Nangapanda sebesar 2,53 dan quarry Aemau sebesar 2,84. Penyerapan (absorption) untuk quarry Nangapanda sebesar 2,81\% dan quarry Aemau sebesar 1,60\%,kadar air agregat quarry Nangapanda sebesar 1,51\% dan quarry Aemau sebesar 1,075\%,agregat yang lolos nomor $200(0,075 \mathrm{~mm})$ quarry Nangapanda sebesar 0,283\% dan quarry Aemau sebesar 0,423\%, keausan agregat quarry Nangapanda sebesar 18,30\% dan quarry Aemau sebesar 12,06\%. Hasil akhir agregat dua quarry ini sudah memenuhi syarat SNI dengan perbandingan karakteristik agregat quarry Aemau lebih baik dari agregat quarry Nangapanda.
\end{abstract}

Kata kunci: konstruksi jalan,agregat,lapis pondasi,quarry

TEKNOSIAR Volume 15, No.1, April 2021

p-ISSN 1907-5197 (versi cetak) e-ISSN 2721-2270 (versi online) 


\section{PENDAHULUAN}

Pembangunan infrastruktur yang sering dilakukan di pulau Flores adalah pembangunan jalan raya. Karena itu dibutuhkan material yang berkualitas baik, sesuai dengan standar yang telah ditetapkan untuk digunakan dalam proses pembangunan tersebut. Untuk jalan raya agregat merupakan bahan utama struktur perkerasannya, sistem perkerasan jalan umumnya mengandung $90-95 \%$ agregat berdasarkan persen berat atau $70-75 \%$ berdasarkan persen volume. (Hardiyatmo, 2019).

Quarry Nangapanda dan quarry Aemau sebagai sumber material yang sering digunakan untuk pembangunan jalan di kabupaten Ende dan Nagekeo juga Kabupaten sekitarnya. Selain digunakan untuk material jalan, agregat dari dua quarry ini juga digunakan untuk pembuatan beton. Dua quarry ini berada di sekitar daerah aliran sungai (DAS), karena itu material tersedia dalam berbagai jenis, mulai dari agregat halus (pasir), agregat kasar (kerikil) dan batu alam (batu kali). Secara visual tekstur material yang berada di dua quarry ini cukup baik, material agregat berwarna kecoklatan.

Tujuan penelitian ini untuk mengetahui karakteristik agregat quarry Nangapanda dan quarry Aemau, dan perbandingannya.

\section{Kajian Literatur Terdahulu}

Beberapa hasil penelitian tentang agregat sebagai bahan lapis perkerasan jalan yang telah dilakukan adalah sebagai berikut:

Michael Kevindie Setyawan Dkk, telah melakukan penelitian tentang "Perbandingan Karakteristik Agregat Kasar Pulau Jawa Dengan Agregat Luar Pulau Jawa Ditinjau Dari Kekuatan Campuran Perkerasan Lentur". Agregat kasar pulau jawa dijadikan sebagai pembanding karena sudah diakui mutunya untuk pembangunan infrastruktur di pulau jawa. Agregat pulau jawa itu berasal dari Pandaan dan Pacitan. Sedangkan untuk agregat kasar dari luar pulau jawa berasal dari Bali dan Kalimantan. Dari hasil penelitian, disimpulkan bahwa agregat kasar pulau Bali dan Kalimantan tidak bisa langsung dipakai untuk laston WC. Namun pencampuran agregat kasar pulau Bali dan Kalimantan bisa dijadikan alternatif solusi. (media.neliti.com>publications).

Supiandi, telah melakukan penelitian tentang "Studi Material Sirtu Darat Dan Sirtu Sungai Untuk Lapis Pondasi Agregat Kelas B". Untuk sirtu darat material diambil dari Sirtu Tebelian, Sirtu Palin dan Sirtu Sibau Hilir. Sedangkan sirtu sungai diambil dari Sirtu Manggala, Sirtu Lauk Rukun dan Sirtu Klakar. Semua sirtu ini terletak di Kalimantan. Dari hasil penelitian, mereka menyimpulkan bahwa hasil uji kekerasan batu dengan uji abrasi semua contoh sirtu sungai maupun sirtu darat memenuhi syarat untuk digunakan sebagai material campuran lapis pondasi agregat kelas B. Dari hasil uji CBR untuk material asli tanpa dipecah rata-rata CBR tercapai yakni $\geq 60 \%$, untuk material sirtu yang dipecah juga tercapai $\geq 60 \%$. (Jurnal.untan.ac.id).

\section{Perkerasan Jalan}

Perkerasan jalan merupakan struktur yang diletakkan pada tanah dasar, yang memisahkan antara ban kendaraan dengan tanah dasar yang ada di bawahnya. Perkerasan harus memberikan permukaan yang rata dengan kekesatan tertentu, dengan umur pelayanan yang cukup panjang serta pemeliharaan yang minimum (Hardiyatmo, 2019). Perkerasan jalan terdiri dari beberapa lapisan yang masing-masing berfungsi untuk meredam gaya atau beban yang disebabkan oleh pergerakan lalulintas di atasnya, sehingga tanah dasar akan tetap stabil.

TEKNOSIAR Volume 15, No.1, April 2021

p-ISSN 1907-5197 (versi cetak) e-ISSN 2721-2270 (versi online) 


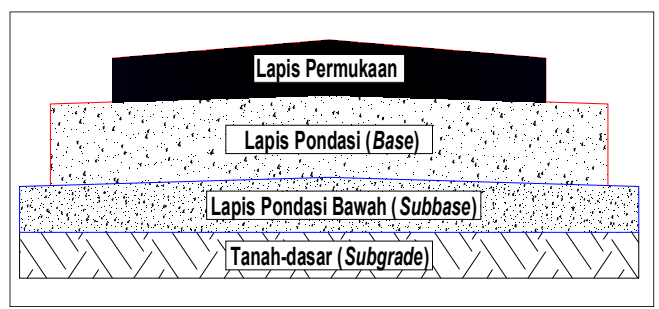

Gambar 1. Susunan lapisan perkerasan jalan Sumber:(Sudarsono,1993)

\section{Lapis Pondasi (Base Course)}

Bahan dasar dari perkerasan, umumnya berupa material granuler yang terdiri dari kerikil atau batu pecah yang mempunyai gradasi tertentu, sehingga membentuk material yang stabil, mudah dikerjakan dan didapatkan.

Persyaratan material pondasi lebih ketat bila dibandingkan dengan lapis pondasi bawah atau tanah dasar. Untuk perkerasan lentur material lapis pondasi (base course) harus didasarkan pada pertimbangan ekonomis antara lain; 1) Kerikil pecah atau tak dipecah,2) Batu pecah bergradasi,3) Macadam,4) Batu kapur,5) Koral,6) Terak (slag).

Material struktur lapisan perkerasan, seperti lapis pondasi, lapis pondasi bawah, dan lapis permukaan terdiri dari campuran material granuler yang secara mekanis harus stabil. Gradasi untuk lapis pondasi (base course), lapis pondasi bawah (subbase course) dan lapis permukaan (surface course) yang tercantum dalam ASTM D 1241, ditunjukkan dalam Tabel 1. Pemilihan gradasi material dalam Tabel 1 masih harus memperhatikan ketahanan (keawetan) dari material yang digunakan. Dalam ASTM D1241.

Tabel 1. Syarat gradasi untuk campuran tanah/agregat (ASTM D-1241)

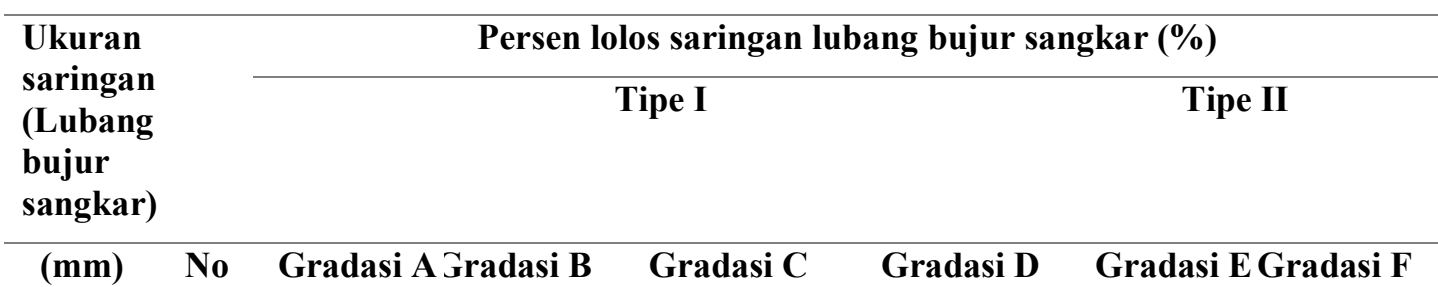

\begin{tabular}{cccccccc}
\hline 50 & $2 "$ & 100 & 100 & - & - & - & - \\
\hline 25 & $1 "$ & - & $75-95$ & 100 & 100 & 100 & 100 \\
\hline 9.5 & $3 / 8 "$ & $30-65$ & $40-75$ & $50-85$ & $60-100$ & - & - \\
\hline 4.75 & 4 & $25-55$ & $30-60$ & $35-65$ & $50-85$ & $55-100$ & $70-100$ \\
\hline 2.0 & 10 & $15-40$ & $20-45$ & $25-50$ & $40-70$ & $40-100$ & $55-100$ \\
\hline 0.425 & 40 & $8-20$ & $15-30$ & $15-30$ & $25-45$ & $20-50$ & $30-70$ \\
\hline 0.075 & 200 & $2-8$ & $5-15$ & $5-15$ & $8-15$ & $6-15$ & $8-25$ \\
\hline
\end{tabular}

Sumber: (Hardiyatmo, 2019) 
Jenis bahan dan gradasi yang diinginkan harus ditetapkan. Dalam ASTM D 2940-98 disyaratkan gradasi untuk lapis pondasi dan lapis pondasi bawah seperti yang ditampilkan dalam Tabel 2.

Tabel 2. Gradasi lapis pondasi dan pondasi bawah (ASTM D 2940-98)

\begin{tabular}{cccc}
\hline No. saringan & Ukuran saringan & \multicolumn{2}{c}{ Gradasi: persen lolos } \\
\cline { 2 - 4 } & $(\mathbf{m m})$ & Lapis pondasi & Lapis pondasi bawah \\
\hline $\mathbf{2}$ & 50 & 100 & 100 \\
\hline $\mathbf{1 . 5}$ & 37.5 & $95-100$ & $90-100$ \\
\hline $\mathbf{3} 4$ & 19 & $70-92$ & - \\
\hline $\mathbf{3 / 8}$ & 9.5 & $50-70$ & - \\
\hline $\mathbf{4}$ & 4.75 & $35-35$ & - \\
\hline $\mathbf{3 0}$ & 0.6 & $12-25$ & $0-12$ \\
\hline $\mathbf{2 0 0}$ & 0.075 & $0-8$ & - \\
\hline
\end{tabular}

Sumber:( Hardiyatmo, 2019)

Departemen Pekerjaan Umum (2005) membagi agregat lapis pondasi menjadi 3 kelas, yaitu: kelas A, B dan C (Tabel 3). Lapis pondasi atas (base) harus terdiri dari kelas A atau B, sedangkan lapis pondasi bawah (subbase) harus terdiri dari kelas C. Rincian fraksi-fraksi dan persyaratan adalah sebagai berikut:

Tabel 3. Gradasi agregat lapis pondasi (DPU, 2005)

\begin{tabular}{|c|c|c|c|c|}
\hline \multicolumn{2}{|c|}{ Ukuran saringan ASTM } & \multicolumn{3}{|c|}{ Persen berat lolos saringan (\%) } \\
\hline Nomor & $\begin{array}{c}\text { Diameter butiran } \\
(\mathrm{mm})\end{array}$ & Kelas A & Kelas B & Kelas C \\
\hline 2" & 50 & - & 100 & 100 \\
\hline $1 \frac{1}{2 \prime \prime}$ & 37.5 & 100 & $88-95$ & $70-100$ \\
\hline 1" & 25 & $77-85$ & $70-85$ & $55-87$ \\
\hline $3 / 8 "$ & 9.5 & $44-58$ & $40-65$ & $40-70$ \\
\hline No. 4 & 4.75 & $27-44$ & $25-52$ & $27-60$ \\
\hline No. 10 & 2.0 & $17-30$ & $15-40$ & $20-50$ \\
\hline No. 40 & 0.425 & $7-17$ & $8-20$ & $10-30$ \\
\hline No. 200 & 0.075 & $2-8$ & $2-8$ & $5-15$ \\
\hline
\end{tabular}

Sumber: (Hardiyatmo, 2019)

Sifat-sifat Agregat untuk lapis pondasi harus bebas dari bahan organik dan gumpalan lempung atau bahan-bahan lain yang tidak dikehendaki, harus memenuhi ketentuan gradasi yang diberikan dalam Tabel 3 dan memenuhi sifat-sifat yang diberikan dalam Tabel 4. 
Blasius D.Nosemba, Thomas Aquino A.S, F.X.Ndale

Studi Perbandingan Karakteristik Agregat Quarry Nangapanda Dan Aemau Untuk Lapis Pondasi Bawah (Sub Base)

Tabel 4. Sifat-sifat agregat lapis pondasi (DPU, 2005)

\begin{tabular}{|c|c|c|c|}
\hline Sifat-sifat & Kelas A & Kelas B & Kelas C \\
\hline Abrasi agregat kasar & Maks. $40 \%$ & Maks. $40 \%$ & Maks. $40 \%$ \\
\hline \multicolumn{4}{|l|}{ (SNI 03-2417-1990) } \\
\hline Indeks plastisitas & Maks. 6 & Maks. 6 & $4-9$ \\
\hline \multicolumn{4}{|l|}{ (SNI 03-1996-1990) } \\
\hline $\begin{array}{c}\text { Hasil kali indeks plastisitas dengan \% lolos } \\
\text { saringan No. } 200\end{array}$ & Maks. 25 & - & - \\
\hline Batas cair (SNI 03-1967-1990) & Maks. 25 & Maks. 25 & Maks. 25 \\
\hline Bagian yang lunak & Maks. $5 \%$ & Maks. $5 \%$ & - \\
\hline CBR (SNI 03-1744-1989) & Min. $90 \%$ & Min. $65 \%$ & Min. $35 \%$ \\
\hline Perbandingan persen lolos & Maks. 2/3 & Maks. 2/3 & Maks. 2/3 \\
\hline No. 200 dan No. 40 & & & \\
\hline
\end{tabular}

\section{Karakteristik Agregat}

Analisis saringan agregat ialah penentuan persentase berat butiran agregat yang lolos satu set saringan kemudian angka-angka persentase digambarkan pada grafik pembagian butir.

Analisa saringan;

$$
\frac{\text { Berat tertahan }}{\text { Berat benda uji }} \times 100 \%
$$

Pengujian berat jenis dan penyerapan agregat adalah untuk menentukan berat jenis curah, berat jenis kering permukaan jenuh, berat jenis semu agregat kasar, serta angka penyerapan dari agregat kasar.

Berat jenis curah (bulk specific gravity);

$$
\frac{B k}{B j-B a}
$$

Berat jenis kering permukaan jenuh (saturated surface dry);

$$
\frac{B j}{B j-B a}
$$

Berat jenis semu (apparent specific gravity);

$$
\frac{B k}{B k-B a}
$$

Penyerapan (absorption);

Keterangan:

$$
\frac{B j-B k}{B k} x 100 \%
$$

$\mathrm{Bk}=$ berat benda uji kering oven (gram)

TEKNOSIAR Volume 15, No.1, April 2021

p-ISSN 1907-5197 (versi cetak) e-ISSN 2721-2270 (versi online) 
$\mathrm{Bj}=$ berat benda uji kering permukaan jenuh (gram)

$\mathrm{Ba}=$ berat benda uji keringpermukaan jenuh dalam air (gram)

Pengujian kadar air agregat untuk menentukan kadar air agregat dan memperoleh angka persentase kadar air yang dikandung oleh agregat. Kadar air agregat adalah besarnya perbandingan antara berat air yang dikandung agregat dengan agregat dalam keadaan kering, dinyatakan dalam persen.

$$
\begin{aligned}
& \text { Kadar air agregat }=\frac{W 3-W 5}{W 5} \times 100 \% \\
& \text { Keterangan: } \\
& \text { W3 = Berat benda uji semula (gram) } \\
& \text { W5 = Berat benda uji kering (gram) }
\end{aligned}
$$

Pengujian jumlah bahan yang lolos saringan No. $200(0,075 \mathrm{~mm})$, adalah banyaknya bahan yang lolos saringan No. $200(0,075 \mathrm{~mm})$ setelah agregat dicuci sampai air cucian menjadi jernih, dan tujuannya adalah untuk memperoleh persentase jumlah bahan dalam agregat yang lolos saringan No. $200(0,075 \mathrm{~mm})$ sehingga berguna bagi perencanaan dan pelaksanaan pembangunan jalan. Perhitungan jumlah bahan dalam agregat yang lolos saringan no. $200(0,075 \mathrm{~mm})$;

Berat kering benda uji awal

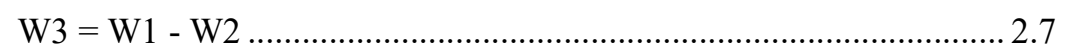

Berat kering benda uji sesudah pencucian



Bahan lolos saringan No. $200(0,075 \mathrm{~mm})$

$$
\mathrm{W} 6=\frac{W 3-W 5}{W 3} \times 100 \%
$$

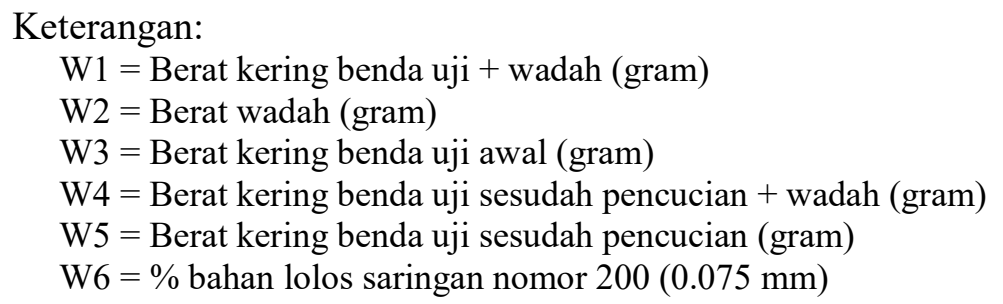

Pengujian keausan agregat untuk menentukan ketahanan agregat kasar terhadap keausan dengan menggunakan mesin Abrasi Los Angeles, angka keausan dinyatakan dengan perbandingan antara berat bahan aus lolos saringan nomor $12(1,7 \mathrm{~mm})$ terhadap berat semula, dalam persen.

Keausan agregat ;

$$
\frac{a-b}{a} \times 100 \%
$$

\section{Keterangan:}

$\mathrm{a}=$ berat benda uji semula (gram)

$\mathrm{b}=$ berat benda uji tertahan saringan No. 12 (gram)

TEKNOSIAR Volume 15, No.1, April 2021 p-ISSN 1907-5197 (versi cetak) e-ISSN 2721-2270 (versi online) 
Blasius D.Nosemba, Thomas Aquino A.S, F.X.Ndale

Studi Perbandingan Karakteristik Agregat Quarry Nangapanda Dan Aemau Untuk Lapis Pondasi Bawah (Sub Base)

\section{METODE}

\section{Bahan dan Alat}

Bahan yang digunakan terdiri dari agregat kasar berasal dari quarry Nangapanda di Kabupaten Ende dan quarry Aemau Kabupaten Nagekeo. Sedangkan alat yang digunakan tersedia di Laboratorium Program Studi Teknik Sipil Fakultas Teknik, Universitas Flores.

\section{Tahapan Penelitian}

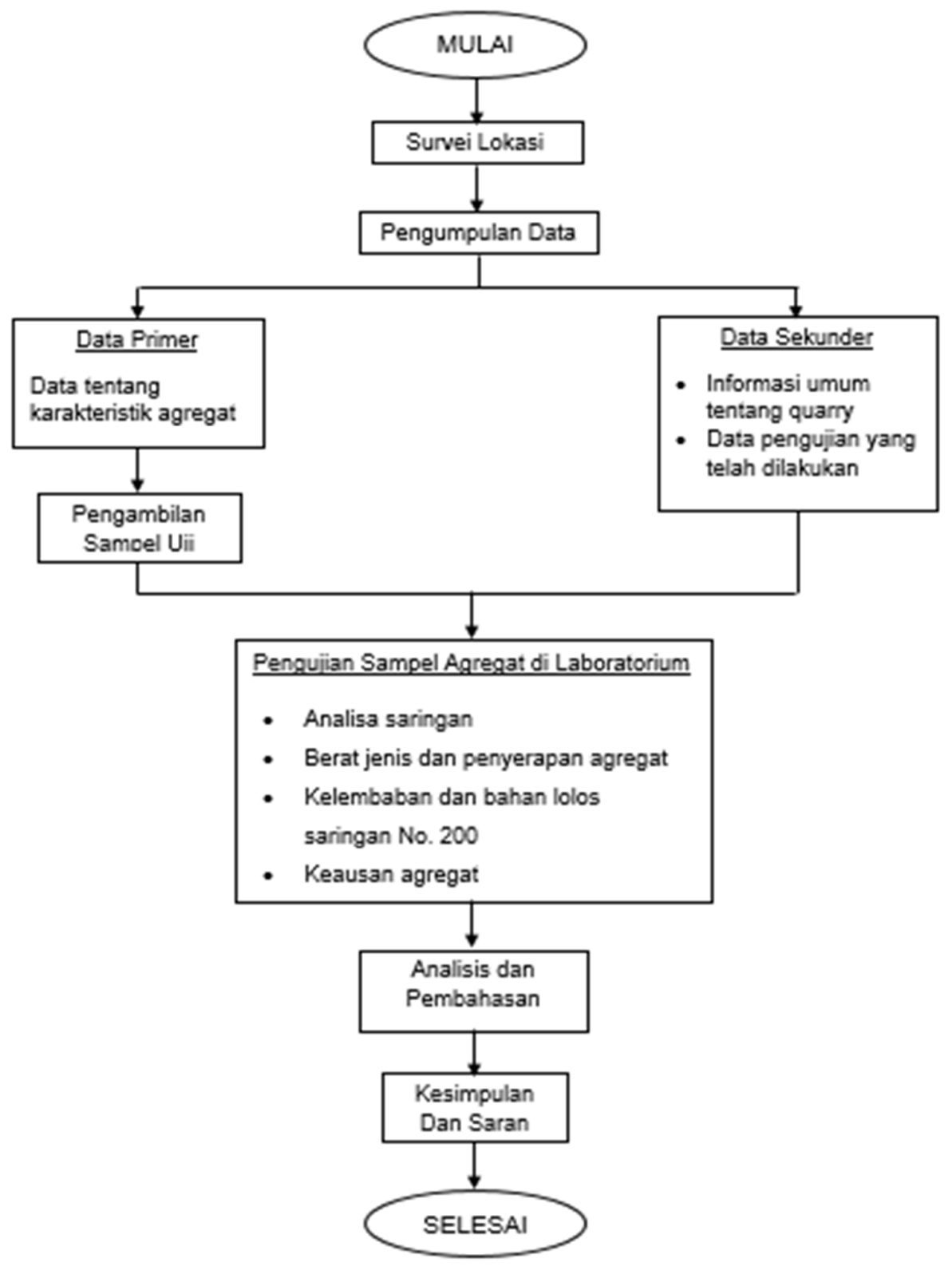

Gambar 2. Tahapan Penelitian

TEKNOSIAR Volume 15, No.1, April 2021

p-ISSN 1907-5197 (versi cetak) e-ISSN 2721-2270 (versi online) 


\section{HASIL DAN PEMBAHASAN}

\section{Karakteristik Agregat}

Hasil analisis pengujian karakteristik agregat dapat dilihat pada Tabel 5 dan Tabel 6:

\section{Tabel 5. Hasil Analisa Agregat Quarry Nangapanda}

\begin{tabular}{lllll}
\hline No. & Percobaan & Hasil & Nilai Standar & Keterangan \\
\hline 1 & Gradasi Butiran & $4,75 \mathrm{~mm}-25.40 \mathrm{~mm}$ & - & Gradasi seragam \\
\hline 2 & Berat Jenis bulk & 2.53 & $2,5-2,7 \mathrm{Kg} / \mathrm{dm}^{3}$ & Memenuhi \\
\hline 3 & Berat Jenis (SSD) & 2.54 & $2,5-2,7 \mathrm{Kg} / \mathrm{dm}^{3}$ & Memenuhi \\
\hline 4 & $\begin{array}{l}\text { Berat jenis } \\
\text { (apparent) }\end{array}$ & 2.65 & $2,5-2,7 \mathrm{Kg} / \mathrm{dm}^{3}$ & Memenuhi \\
\hline 5 & Penyerapan Air & $2,81 \%$ & Maks.3\% & Memenuhi \\
\hline 6 & Kadar Air & $1,51 \%$ & - & Memenuhi \\
\hline 7 & Kadar Keausan & $18,30 \%$ & $\leq 27 \%$ & Memenuhi \\
\hline 8 & $\begin{array}{l}\text { Agregat lolos saringan } \\
\text { no.200 } 0,283 \%\end{array}$ & $<12 \%$ & \\
\hline & $\begin{array}{l}\text { Sumber : (Hasil Analisis 2021) } \\
\end{array}$ & & &
\end{tabular}

Berdasarkan Tabel 5, hasil gradassi butiran termasuk dalam gradasi seragam atau gradasi terbuka (open graded), karena mengandung sedikit agregat halus yakni $0,100 \%$ lolos saringan nomor 4 $(4,75 \mathrm{~mm})$ dan agregat berukuran hampir sama/sejenis yakni 87,243\% agregat tertahan di saringan nomor 1" $(25,4 \mathrm{~mm})$. Nilai berat jenis (bulk) 2,53 dan nilai ini lebih besar dari 2,50 karena itu memenuhi syarat minimum, nilai berat jenis kering permukaan jenuh 2,54 , nilai berat jenis semu (apparent) 2,65 dan nilai penyerapan agregat 2.81\% lebih kecil dari 3\% karena itu memenuhi syarat penyerapan (absorption). Jumlah bahan yang lolos saringan nomor $200(0,075 \mathrm{~mm})$ sebesar $0,283 \%$, jumlah ini lebih kecil dari syarat untuk lapis pondasi bawah yakni $12 \%$, karena itu memenuhi syarat. Nilai keausan agregat sebesar $18,30 \%$, nilai ini lebih kecil dari nilai standar keausan yaitu sebesar $40 \%$, maka memenuhi syarat keausan.

Tabel 6. Hasil Analisa Agregat Quarry Aemau

\begin{tabular}{lllll}
\hline No. & Percobaan & Hasil & Nilai Standar & Keterangan \\
\hline 1 & Gradasi Butiran & $4,75 \mathrm{~mm}-25.40 \mathrm{~mm}$ & & Gradasi seragam \\
\hline 2 & Berat Jenis bulk & 2.84 & $2,5-2,7 \mathrm{Kg} / \mathrm{dm}^{3}$ & Memenuhi \\
\hline 3 & Berat Jenis (SSD) & 2.88 & $2,5-2,7 \mathrm{Kg} / \mathrm{dm}^{3}$ & Memenuhi \\
\hline 4 & $\begin{array}{l}\text { Berat jenis semu } \\
\text { (apparent) }\end{array}$ & 2.97 & $2,5-2,7 \mathrm{Kg} / \mathrm{dm}^{3}$ & Memenuhi \\
\hline 5 & Penyerapan Air $1,60 \%$ & Maks.3\% & Memenuhi \\
\hline 6 & Kadar Air & $1,075 \%$ & - & Memenuhi \\
\hline 7 & Kadar Keausan & $12,06 \%$ & $\leq 27 \%$ & Memenuhi \\
\hline 8 & $\begin{array}{l}\text { Agregat lolos } \\
\text { saringan no.200 }\end{array}$ & $0,423 \%$ & $<12 \%$ & \\
\hline & Sumber : (Hasil Analisis 2021) & & \\
\hline
\end{tabular}

Berdasarkan Tabel 6, hasil gradasi butiran termasuk dalam tipikal gradasi seragam atau gradasi terbuka (open graded), karena mengandung sedikit agregat halus yakni $0,179 \%$ lolos saringan nomor $4(4,75 \mathrm{~mm})$ dan agregat berukuran hampir sama/sejenis yakni 87,366 \% agregat tertahan di

TEKNOSIAR Volume 15, No.1, April 2021

p-ISSN 1907-5197 (versi cetak) e-ISSN 2721-2270 (versi online) 
saringan nomor 1" (25,4 mm). Nilai bertat jenis (bulk) 2,84 dan nilai ini lebih besar dari 2,50, maka memenuhi syarat, nilai berat jenis kering permukaan jenuh 2,88, nilai berat jenis semu (apparent) 2,97 dan nilai penyerapan 1,60\% lebih kecil dari 3\% karena itu memenuhi syarat penyerapan (absorption). Jumlah bahan yang lolos saringan nomor 200 sebesar $0,432 \%$, jumlah ini lebih kecil dari syarat $12 \%$, karena itu memenuhi syarat. Nilai keausan agregat sebesar $12,06 \%$, nilai ini lebih kecil dari nilai standar keausan sebesar 40\%, maka memenuhi syarat keausan.

\section{KESIMPULAN}

Berdasarkan hasil analisis dan pembahasan, maka dapat disimpulkan sebagai berikut :

1. Karakteristik agregat yang meliputi gradasi butiran,berat jenis,kadar air,jumlah bahan yang lolos saringan nomor 200,serta nilai keausan agregat dari hasil analisis menunjukkan agregat quarry Nangapanda dan quarry Aemau telah memenuhi syarat SNI 1969:2008.

2. Mutu atau kualitas agregat menunjukkan bahwa agregat quarry Aemau lebih baik jika dibandingkan dengan agregat quarry Nangapanda.

\section{UCAPAN TERIMA KASIH}

1. Terima kasih kepada Kepala Laboratorium Teknik Sipil Universitas Flores

2. Terima kasih kepada pihak-pihak yang telah membantu dalam proses penelitian

\section{DAFTAR PUSTAKA}

Hardiyatmo, Hary Christady, 2019. Perancangan Perkerasan Jalan Dan Penyelidikan Tanah: Perkerasan Aspal, Perkerasan Beton, Sistem Cakar Ayam Modifikasi, Sistem Pelat Terpaku, edisi 3. Yogyakarta, Gadja Mada University Press.

Sudarsono, Djoko Untung, 1993. Konstruksi Jalan Raya. Jakarta, Yayasan Badan Penerbit Pekerjaan Umum.

SNI 6889: 2014, Tata Cara Pengambilan Contoh Uji Agregat (ASTM d75/D75M-09, IDT). Jakarta: Badan Standar Nasional.

SNI 03-6388-2000, Spesifikasi Agregat Lapis Pondasi Bawah, Lapis Pondasi Atas Dan Lapis Permukaan. Jakarta: Pustran - Balitbang Pekerjaan Umum.

SNI 03-1968-1990, Metode Pengujian Tentang Analisis Saringan Agregat Halus Dan Kasar. Jakarta: Pustran - Balitbang Pekerjaan Umum.

SNI 03-1969-1990, Metode Pengujian Berat Jenis Dan Penyerapan Agregat Kasar. Jakarta: Pustran - Balitbang Pekerjaan Umum.

SNI 03-1971-1990, Metode Pengujian Kadar Air Agregat. Jakarta: Pustran - Balitbang Pekerjaan Umum.

SNI 03-4142-1996, Metode Pengujian Jumlah Bahan Dalam Agregat Yang Lolos Saringan No. $200(0,075 \mathrm{~mm})$. Jakarta: Pustran - Balitbang Pekerjaan Umum.

SNI 03-2417-1991, Metode Pengujian Keausan Agregat Dengan Mesin Abrasi Los Angeles. Jakarta: Pustran - Balitbang Pekerjaan Umum.

TEKNOSIAR Volume 15, No.1, April 2021

p-ISSN 1907-5197 (versi cetak) e-ISSN 2721-2270 (versi online) 
Kevindie Setyawan, Michael, Sri Wulandari, Paravita and Patmadjaja, Harry; Perbandingan Karakteristik Agregat Pulau Jawa dan Luar Pulau Jawa Ditinjau Dari Kekuatan Campuran Perkerasan lentur. (Online), (http://jurnal.untan.ac.id/index.php/jtsuntan/article/downlo$\mathrm{ad} / 24727 / 75676576204$, diakses 21 Agustus 2020).

Supiandi, Studi Material Sirtu Darat Dan Sirtu Sungai Untuk Lapis Pondasi Agregat Kelas B. (Online), (https://jurnal.untan.ac.id/index.php/ jtsuntan/article/viev/24727, diakses 21 Agustus 2020). 